УДК 594.1:551.468.3(262.54)

\title{
СТРУКТУРНЫЕ ХАРАКТЕРИСТИКИ ПОПУЛЯЦИИ ДВУСТВОРЧАТОГО МОЛЛЮСКА LENTIDIUM MEDITERRANEUM (O.G. COSTA, 1829) В ЮЖНОЙ ЧАСТИ АЗОВСКОГО МОРЯ*
}

Алёмов С.В. ${ }^{1}$, Алёмова А.С. $^{2}$

${ }^{I}$ ФББУН ФИЦ «Институт биологии южных морей имени А.О. Ковалевского РАН»,

2. Севастополь, Российская Федерачия, e-mail:alyomov_sv@ibss-ras.ru

${ }^{2}$ ФББОУ ВО «Воронежский государственный университет»,

2. Воронеж, Российская Федераичия

Для изучения масс-размерных характеристик L. mediterraneum пробы были отобраны в июле 2016 г. в Южной части Азовского моря у основания мыса Казантип. Всего измерено 3021 экземпляр L. mediterraneum, индивидуальный вес определён для 671 экземпляров. Составлены размерно-частотные гистограммы для поселений L. mediterraneum в прибрежной зоне бухт Русская и Татарская. В исследованных популяциях присутствуют молодь (сеголетки) и особи 2го года жизни. В составе локального поселения в б. Русская преобладают особи с длиной раковины 1,6-1,9 мм - около 50 \% общего количества. В результате проведенных измерений получен ряд степенных уравнений, связывающих высоту раковины с общей массой моллюска. Уравнения, полученные на основе данных по средней массе моллюсков всех размерных групп с диапазоном 1 мм имеют вид: $\mathrm{M}=0,417 \mathrm{~L}^{2,38}$ для б. Русская и $\mathrm{M}=0,321 \mathrm{~L}^{2,41}$ для б. Татарская, и демонстрируют высокую степень достоверности. В б. Татарская отмечается более низкие значения средней массы моллюсков размерных групп 4-7 мм по сравнению с популяцией в б. Русская.

Ключевые слова: Азовское море; двустворчатые моллюски; популяция; размерная структура.

\section{Введение}

Макрозообентос - это неотьемлемая составляющая часть экосистемы любых водоёмов, которая играет чрезвычайно важную роль в функционировании водных экосистем. Макробеспозвоночные, обитающие на поверхности и в толще грунта, являющиеся по типу питания фильтраторами и собирателями (детритофаги), играют огромную роль в самоочищении водоёма, формируя тем самым качество среды обитания. Для многих видов рыб, в том числе промысловых, организмы зообентоса являются одним из основных компонентов рациона. Получение фактических данных о видовой структуре донных биоценозов, количественных характеристик, входящих в них видов, выявление пространственных и временных особенностей в распределении бентоса, создает возможности для более объективного прогнозирования изменений в ихтиофауне исследуемых районов.

Роль моллюсков в бентосных сообществах Азовского моря давно определена как доминирующая, а сам водоем В.П. Воробьев называл «...моллюсочным морем» (Воробьев, 1949). Один из широко распространённых видов двустворчатых моллюсков в Азово-Черноморском бассейне- лентидиум средиземноморский (Lentidium mediterraneum (O.G. Costa, 1829)). У побережья Румынии, в северо-западной части Чёрного моря от устья Дуная до Одесского залива, в Азовском море он является руководящим видом одноименного биоценоза (Киселева, 1981; Варигин, 2005, 2010; Анистратенко, Халиман, Анистратенко, 2011). Биоценоз лентидиума представляет благоприятную кормовую базу для ряда промысловых видов рыб (Виноградов, 1959;

\footnotetext{
* Работа выполнена в рамках государственного задания ФИЦ ИнБЮМ по теме «Молисмологические и биогеохимические основы гомеостаза морских экосистем», № AAAAA18-118020890090-2.
} 
Болтачев и др., 2016). Как активный фильтратор, лентидиум вносит существенный вклад в процессы самоочищения в прибрежной зоне моря. При максимальной плотности поселений лентидиума (до 150000 экз./ $\mathrm{M}^{2}$ ) объем биофильтра может достигать 26 тыс. л в сутки (Киселева, 1981). Широкая распространенность и доступность (небольшие глубины обитания) делают этот вид удобным для использования как индикатора состояния прибрежных морских экосистем (Dumitrache et al., 2008). Для Румынского побережья и Одесского залива определены показатели масс-размерных соотношений у L. mediterraneum (Gomoiu,1965; Варигин, 2010), тогда как в Азовском море подобные исследования не проводились.

У побережья Казантипского заповедника L. mediterraneum встречается, как

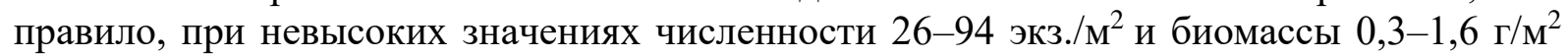
(Болтачев и др., 2016). Однако, в мелководных песчаных бухтах в основании мыса (б. Татарская, б. Русская), отмечено его массовое поселение с численностью более 15000

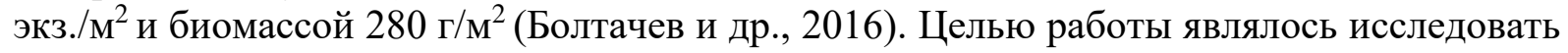
размерный состав и определить показатели масс-размерных соотношений локального поселения L. mediterraneum в б. Русская и б. Татарская.

\section{Материалы и методы}

Для изучения масс-размерных характеристик L. mediterraneum пробы были отобраны в июле 2016 года в основании мыса Казантип в прибрежной части бухт Русская и Татарская (рис. 1) при помощи водолазного дночерпателя с площадью захвата $0,08 \mathrm{~m}^{2}$ на глубине 1 м. Собранный материал промывали через сита с минимальным размером ячеи 1 мм. Пробу фиксировали 96\% этанолом.

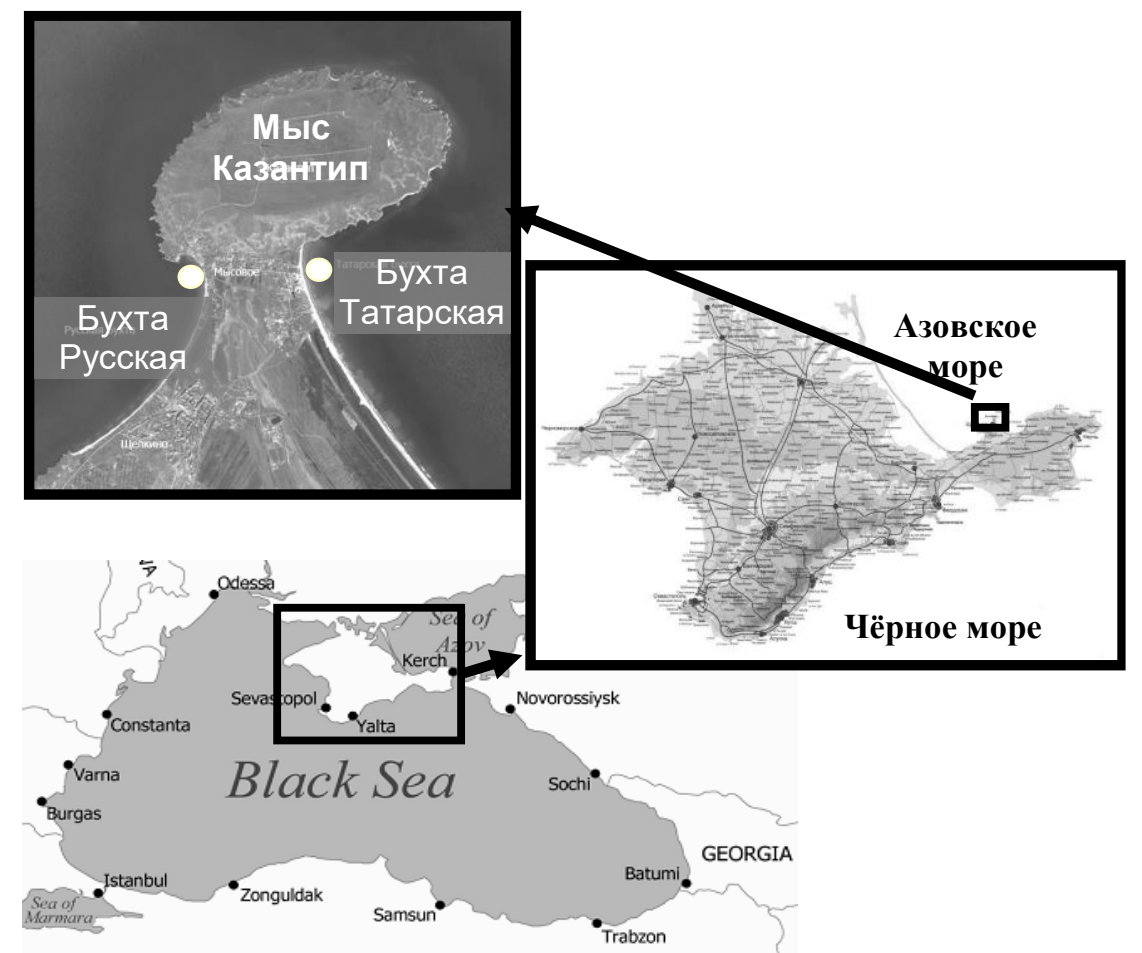

Рис. 1. Схема расположения места отбора проб

Последующая обработка фиксированного материала проводилась в лабораторных условиях. Длину раковины определяли с точностью до 0,1 мм с помощью окулярмикрометра. Массу моллюска определяли с точностью до 0,0001 г. на аналитических весах ВЛР-200. Перед взвешиванием моллюсков вскрывали препаровальной иглой для 
удаления фиксирующего раствора из мантийной полости, затем просушивания на фильтровальной бумаге.

Для моллюсков размерных групп свыше 4 мм определяли индивидуальную массу (сырых тканей вместе со створками), для моллюсков менее 4 мм определяли суммарную массу по группам: до 2 мм, 2,0-2,9 мм, 3,0-3,9 мм с последующим расчётом средней индивидуальной массы.

Всего измерено 3127 экземпляр L. mediterraneum, индивидуальный вес определён для 671 экземпляров. Полученные данные представляли в виде степенного уравнения (Заика, 2004; Варигин, 2010):

$$
M=a L^{b}
$$

где $M$ - масса моллюска со створками (мг), $L$ - длина моллюска (мм), $a$ и $b-$ постоянные величины ( $a$ - коэффициент пропорциональности, $b$ - основная искомая аллометрическая постоянная).

Определение возраста моллюска проводили посредством определения колец задержки роста, формирующимися на наружной поверхности раковины с годовой периодичностью (Уваева, Михайлова, 2017). Измеряли длину раковины от макушки до наиболее удаленной части годового кольца. Возраст был определён для 106 экземпляров лентидиума с длиной створок от 5 до 7 мм.

\section{Результаты и обсуждение}

В составе локального поселения в б. Русская преобладают особи с длиной раковины 1,6-1,9 мм - около 50 \% общего количества (рис. 2). В составе размерной группы 1-3,9 мм наибольшее количество отмечено для особей с длиной раковины 1,71,9 мм. В составе размерной группы свыше 4 мм отмечено два локальных пика с максимами 4,9 мм и 5,5 мм. Возможно, это связано с наличием двух пиков размножения у лентидиума.

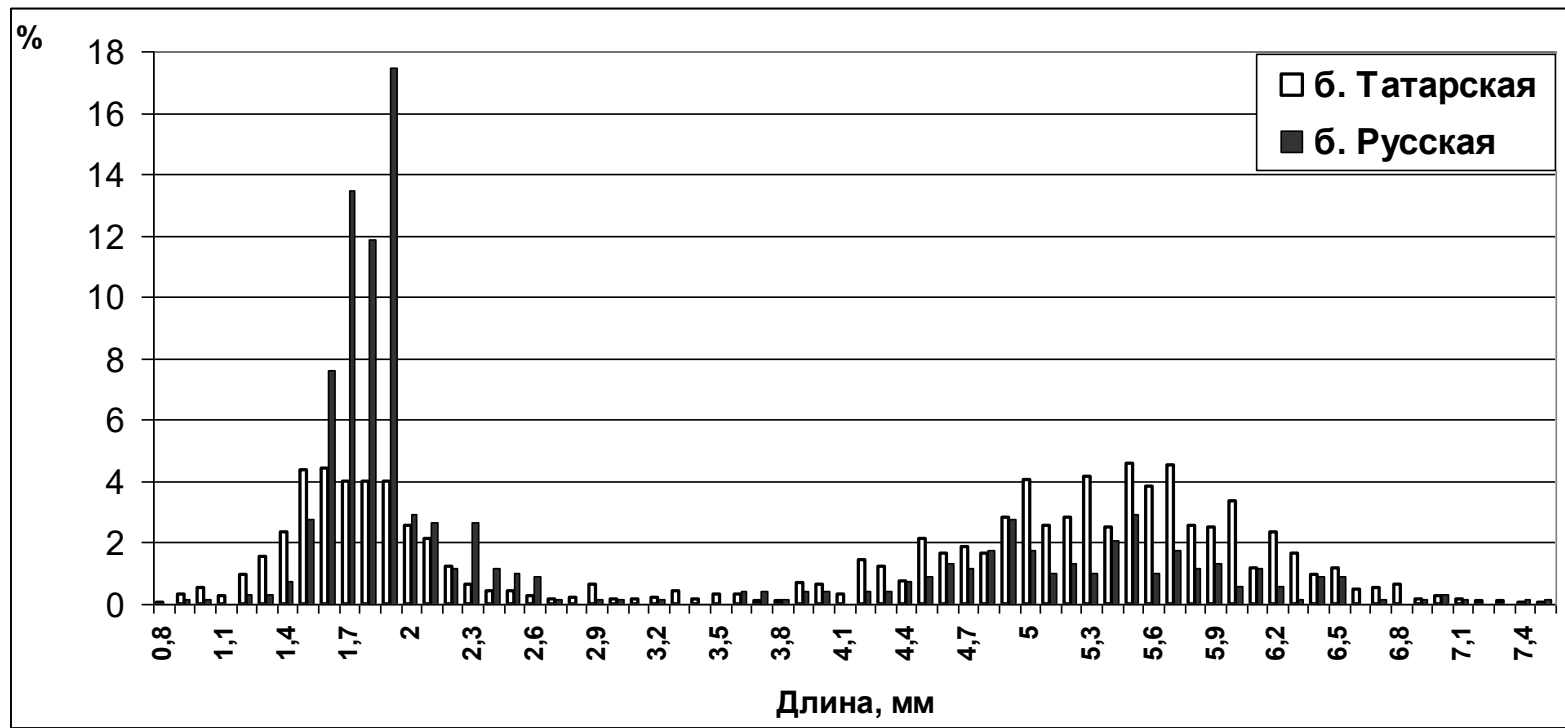

Рис. 2. Размерная структура для поселений L. mediterraneum в б. Русская и б. Татарская

В составе локального поселения в б. Татарская доля особей с длиной раковины 1,4-2,0 мм и 4,9-5,9 примерно одинакова (рис. 2). Таким образом, в б. Татарская, при общей более высокой плотности популяции, значительно выше количество особей старших возрастных групп. Особи с длиной раковины более 6,5 мм в обеих бухтах встречены в небольшом количестве, что может быть вызвано выеданием более крупных моллюсков бентосоядными рыбами. 
Длина раковины у лентидиума обычно до 10 мм (редко до 12 мм) (Киселева, 1981; Анистратенко, Халиман, Анистратенко, 2011). Есть сведения, что особи лентидиума в Азовском море вырастают в течение первого года до 6-7 мм (Старк, 1955; Карпевич, 1964). В исследованиях в прибрежье м. Казантип, проведенных в мае 2011 г., моллюски размерной группы 1-2 мм присутствовали в минимальном количестве, а размерная группа 2-3 мм отсутствовала. Единично были отмечены особи длиной до 7 мм, а большинство моллюсков (60\%) имели длину раковины не более 5 мм (Болтачев и др., 2016). Следовательно, группу моллюсков размером до 3,0 мм, очевидно, можно отнести к сеголеткам, что указывает на наличие пика размножения лентидиума в конце весны начале лета.

В ходе работы была составлена гистограмма длины первого годового кольца (рис. 3А). Его длина колебалась от 3 до 5,1 мм. Анализ возрастной структуры популяций по группам размеров показал, что за год наибольшее количество моллюсков вырастает на 4-4,5 мм (рис 3Б). Средний размер моллюсков в возрасте 1 год составил 4,3 мм. Моллюски с двумя годовыми кольцами не выявлены, следовательно, в исследованных популяциях присутствуют молодь (сеголетки) и особи 2-го года жизни. Присутствие особей размерных групп от 3-3,8 и более 5 мм в небольшом количестве можно объяснить тем, что эти значения являются крайними значениями в диапазоне роста моллюска.
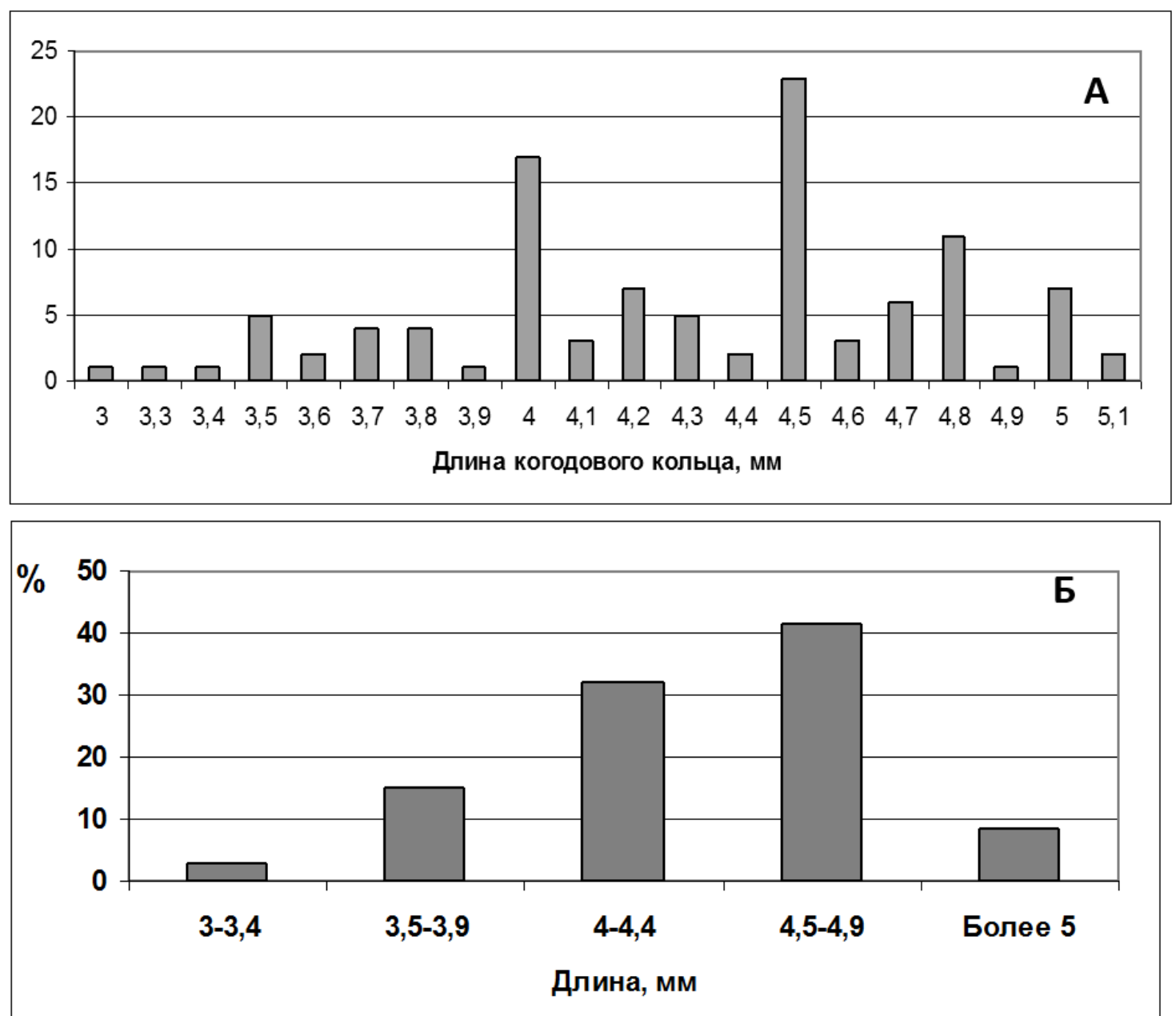

Рис. 3. Количество особей L. mediterraneum с различной длиной годового кольца (общее - A, по размерным группам - Б).

На гистограммах размерной структуры поселений лентидиума (рис. 2) видно, что в б. Русской количество сеголеток значительно превышает количество особей, возраст которых больше одного года. Это может быть связано с большим прессом хищников в 
б. Русская, которые выедают из популяции моллюсков возрастом больше года (размерных групп от 4,5 до 6,5 мм). В б. Татарская располагается городской пляж, и популяция лентидиума менее подвержена влиянию хищников, поэтому присутствует два примерно одинаковых пика молоди и годовиков.

Для побережья Румынии отмечено, что на глубинах до 1 м более 80 \% популяции лентидиума составляют особи длиной 4-6 мм. Молодь (моллюски менее 1,5 мм) отмечены на глубине 1,7-15 м. Данный факт объясняется разрушающим влиянием прибоя на молодь, а также пассивным переносом течениями и активной миграцией взрослых особей в прибрежье (Gomoiu, 1965). Присутствие молоди лентидиума на глубинах до 1 м в исследованных бухтах, очевидно, связано с особенностями гидрологии Азовского моря (менее интенсивное волновое воздействие), а также отсутствием подходящего для данного вида субстрата на глубинах более 3-4 м.

В результате проведенных измерений получен ряд степенных уравнений, связывающих высоту раковины с общей массой моллюска. Длина раковины исследованных моллюсков была в пределах от 0,58 мм до 7,5 мм. Размах колебаний показателей общей массы моллюсков составлял 0,6-40,4 мг. Уравнения, полученные на основе данных по средней массе моллюсков различных размерных групп с диапазоном 1 мм имеют вид: $\mathbf{M}=0,417 \mathrm{~L}^{2,38}$ для б. Русская и $\mathrm{M}=0,321 \mathrm{~L}^{2,41}$ для б. Татарская, и демонстрируют высокую степень достоверности (рис. 4).

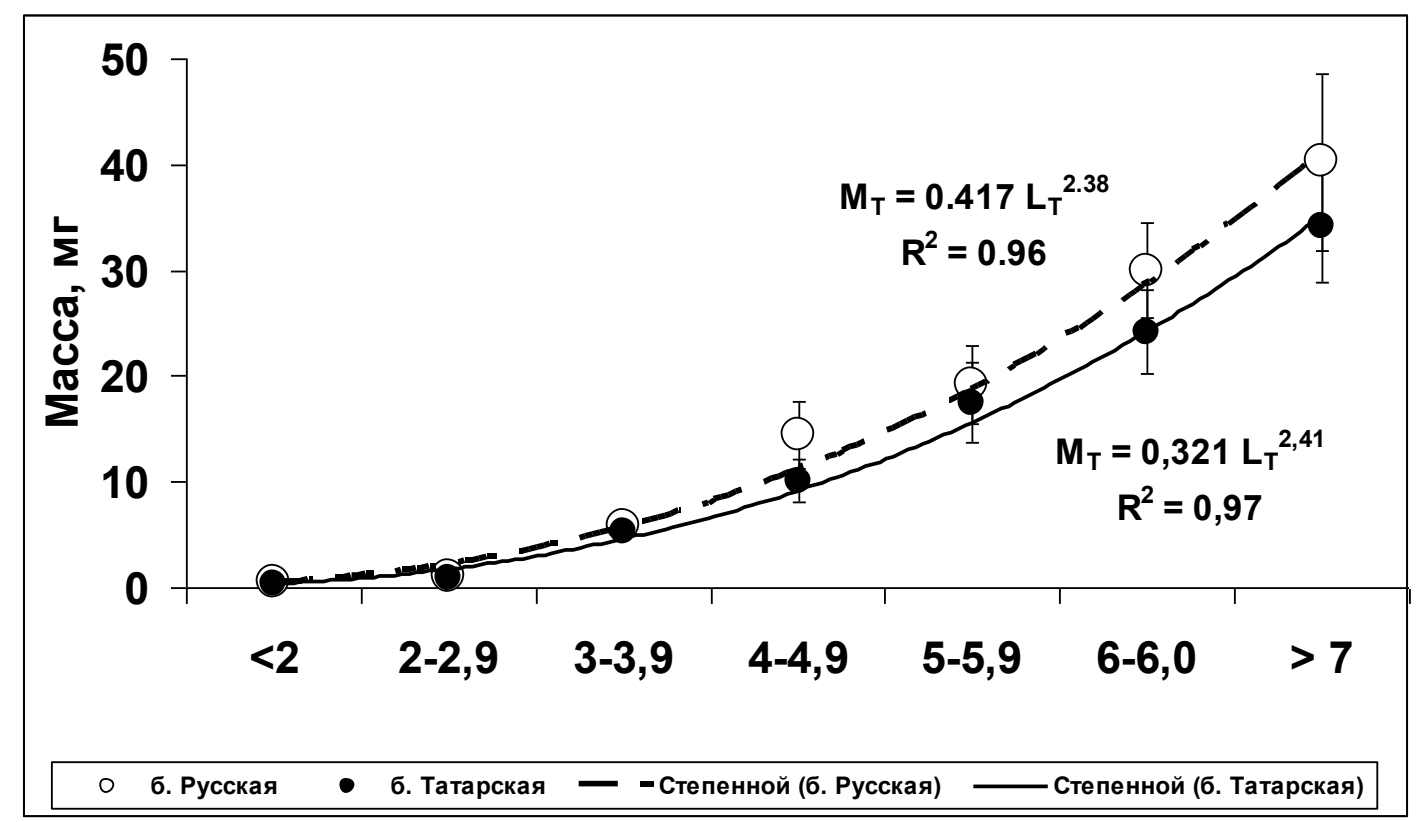

Рис. 4. Зависимость общей массы моллюска и длины раковины L. mediterraneum

Расчеты, проведенные для отдельных размерных групп, показали разные значения коэффициентов и различную степень достоверности полученных зависимостей (табл. 1). В б. Русская у моллюсков с длиной раковины 4,0-4,9 мм и 5,0-5,9 мм результаты не столь точные, так как коэффициент корреляции уравнений находится в пределах от 0,31 до 0,37. При размерах моллюсков от 6,0 мм до 7,5 мм показатели масс моллюсков более тесно связанны с длиной их раковины.

В б. Татарская во всех указанных размерных группах коэффициенты корреляции достаточно высоки $(0,62-0,75)$. Возможно, это связано с гораздо большей представленностью данных размерных групп в локальной популяции. При этом, в б. Татарская отмечается тенденция снижения средней массы моллюсков этих размерных групп по сравнению с популяцией в б. Русская. Возможно это связано со значительно большей плотностью популяции (в 4-5 раз) в этом районе. 
Таблица 1.

Параметры зависимости общей массы моллюска от длины раковины L. mediterraneum различных размерных групा

\begin{tabular}{|c|c|c|c|c|c|c|}
\hline \multirow{2}{*}{ Размерная группа, мм } & \multicolumn{3}{|c|}{ Бухта Русская } & \multicolumn{3}{|c|}{ Бухта Татарская } \\
\cline { 2 - 7 } & $\mathrm{a}$ & $\mathrm{b}$ & $\mathrm{R}^{2}$ & $\mathrm{a}$ & $\mathrm{b}$ & $\mathrm{R}^{2}$ \\
\hline $4,0-4,9$ & 0,389 & 2,34 & 0,31 & 0,125 & 2,87 & 0,62 \\
\hline $5,0-5,9$ & 0,361 & 2,33 & 0,37 & 0,06 & 3,29 & 0,75 \\
\hline $6,0-7,5$ & 0,530 & 2,19 & 0,68 & 0,109 & 2,92 & 0,66 \\
\hline
\end{tabular}

На основании полученных данных, можно сказать, что обе популяции находятся в стабильном состоянии, потому что если взять размерную группу моллюсков 4,56,5 мм, то есть моллюсков примерно одного возраста, то мы увидим, что все особи в популяции стремятся к среднему значению роста. Отбор в пользу средних значений является показателем стабилизирующего естественного отбора, который присутствует в популяциях, находящихся в стабильном состоянии.

\section{Выводы}

1. Анализ размерно-частотных гистограмм для поселений L. mediterraneum в двух бухтах южной части Азовского моря (бухты Русская и Татарская) указывает на наличие двух возрастных групп - сеголеток и годовиков в составе популяции. В б. Татарская доля сеголеток значительно превышает количество годовиков.

2. Определены показатели уравнения масс-размерных характеристик локальных поселений L. mediterraneum в южной части Азовского моря. Уравнения, полученные на основе данных по средней массе моллюсков всех размерных групп имеют вид: $\mathrm{M}=$ $0,417 \mathrm{~L}^{2,38}$ для б. Русская и $\mathrm{M}=0,321 \mathrm{~L}^{2,41}$ для б. Татарская.

3. Характер распределения особей различных размерных групп в локальных поселениях бухт примерно одинаков (преобладают особи с длиной раковины 1,4-2,0 мм и 4,9-5,9 мм), но показатели уравнений масс-размерных характеристик несколько различаются. В б. Татарская отмечается более низкие значения средней массы моллюсков размерных групп 4-7 мм по сравнению с популяцией в б. Русская.

4. В исследованных бухтах особи L. mediterraneum за год вырастают до 3,5-5 мм. Средний размер моллюсков в возрасте около 1 года составляет 4,3 мм.

\section{Список литературы}

1. Анистратенко В.В., Халиман И.А, Анистратенко О.Ю. Моллюски Азовского моря. - Киев: Наукова думка, 2011. - 184 с.

2. Болтачев А.Р., Алемов С.В., Загородняя Ю.А., Карпова Е.П., Манжос Л.А., Губанов В.В, Литвинюк Н.A. Подводный мир Казантипского природного заповедника: К 15-летию Казантипского природного заповедника / Под общ. ред. А. Р. Болтачева, Ю.А. Загородней. - Симферополь: «Бизнес-Информ», 2016. - 112 с.

3. Варигин А.Ю. Аллометрические характеристики двустворчатого моллюска Abra ovata (PHILIPPI, 1836) в условиях северо-западной части Черного моря // Наук. зап. Терноп. нац. пед. ун-ту. Сер. Биол. - 2010. - № 3 (44). - С. 38-40.

4. Варигин А.Ю. Современное состояние поселений Lentidium mediterraneum в прибрежных районах северо-западной части Черного моря // Наукові записки Тернопільського національного педагогічного університету імені Володимира Гнатюка. Серія: Біологія. - 2005. - № 4(27). - С. 32-34.

5. Виноградов К.О. До питання про кормові площі донних рыб північно-західної частини Чорного моря // Наук. зап. Одес. біол. ст. - 1959. - Вып. 1. - С. 98-112.

6. Воробьев В.П. Бентос Азовского моря. - Симферополь: Крымиздат, 1949. - 190 с. 
7. Заика В.E. Аллометрия раковины двустворчатых моллюсков // Морск. экол. журн. 2004. - № 1, T. 3. - С. 47-50.

8. Карпевич А.Ф. Особенности размножения и роста двустворчатых моллюсков солоноватых морей СССР. - В кн. Экология беспозвоночных южных морей СССР. М.: Наука, 1964. - С. 3-60.

9. Киселёва М.И. Бентос рыхлых грунтов Черного моря. - Киев: Наукова думка, 1981. $168 \mathrm{c.}$

10. Старк И.Н. Некоторые данные по биологии корбуломии и других моллюсков // Тр. Азово-Черном. НИИ мор. Рыб. Хоз-ва и океанографии. - 1955. - Вып. 16. - С. 311-326.

11. Уваева Е.И., Михайлова Ю.В. Определение индивидуального возраста у моллюсков // Біологічні дослідження - 2017: Збірник наукових праць. - Житомир: ПП «Рута», 2017. - 103-104.

12. Dumitrache C., Abaza V., Mihnea R., Varga L., Gheorghe L. Establishing the ecological quality status using benthic invertebrates as bio-indicators in marine monitoring // Cercetari marine.- 2008.- №38.- P.119-135.

13. Gomoiu M. The dynamics of Aloidis population // Rev. roum. biol. Ser. Zool. - 1965. - 10, N 5. - P. 353-360.

\section{POPULATION CHARACTERISTICS OF THE BIVALVE LENTIDIUM MEDITERRANEUM (O.G. Costa, 1829) IN THE SOUTH PART OF THE AZOV SEA Alyomov S.V. ${ }^{1}$, Alyomova A.S. ${ }^{2}$ \\ ${ }^{I}$ A. O. Kovalevsky Institute of Biology of the Southern Seas of RAS, Sevastopol, Russian Federation, e-mail:alyomov_sv@ibss-ras.ru \\ ${ }^{2}$ Voronezh State University, Voronezh, Russian Federation}

To study the mass-size characteristics of L. mediterraneum, samples were taken in July 2016 in the southern part of the sea of Azov at the base of Cape Kazantip. A total of 3,021 specimens of L. mediterraneum were measured, and the individual weight was determined for 671 specimens. The size - frequency histograms for the settlements of L. mediterraneum in the coastal zone of The Russian and Tatar bays were compiled. In the investigated populations, there are juveniles (fingerlings) and individuals of the 2nd year of life. The local settlement in Russian Bay is dominated by individuals with a shell length of 1.6-1.9 $\mathrm{mm}$ - about $50 \%$ of the total number. As a result of the measurements, a number of power equations were obtained that relate the height of the shell to the total mass of the mollusk. The equations obtained from the data on the average mass of mollusks of all size groups with a range of 1 $\mathrm{mm}$ are: $\mathrm{M}=0,417 \mathrm{~L}^{2,38}$ for the Russian bay and $\mathrm{M}=0,321 \mathrm{~L}^{2,41}$ for $\mathrm{b}$. Tatarskaya bay, and demonstrate a high degree of confidence. In the Tatarskaya bay, the average mass of mollusks of size groups $4-7 \mathrm{~mm}$ is lower than in the Russian bay population.

Key words: the Azov sea; bivalve molluscs; population; size structure.

Алёмов

Сергей

Викторович

Алёмова

Александра

Сергеевна кандтдат биологических наук, старший научный сотрудник, ведущий научный сотрудник отдела морской санитарной гидробиологии, ФГБУН ФИЦ «Институт биологии южных морей имени A.O. Ковалевского РАН», e-mail: alyomov_sv@ibss-ras.ru

студент медико-биологического факультета, ФГБОУ ВО «Воронежский государственный университет», e-mail: simacoffee@ mail.ru 